\title{
ANALYSIS OF FORMING OF THE PROFESSIONAL COMPETENCE AND THE RATIONAL USE OF HUMAN CAPITAL IN THE DIGITAL ECONOMY
}

\author{
ENDOVITSKY A.Dmitry ${ }^{1}$, TINYAKOVA I.Viktoriya ${ }^{2}$, MOROZOVA I.Natalia ${ }^{3}$, \\ KARYAGINA V. Tatyana ${ }^{4}$, FEDOTOVA A.Marina ${ }^{5}$
}

${ }^{I}$ Voronezh State University, Voronezh (RUSSIA)

${ }^{2}$ State University of Management, Moscow (RUSSIA)

${ }^{3}$ Volgograd Cooperative Institute (branch), of the Russian University of Cooperation, Volgograd (RUSSIA)

${ }^{4}$ Russian State Social University, Moscow (RUSSIA)

${ }^{5}$ Moscow Aviation Institute, Moscow (RUSSIA)

E-mail: eda@econ.vsu.ru; tviktoria@yandex.ru; miss.natalay2012@yandex.ru; zolinatv@mail.ru; fedotova-ma@yandex.ru

\begin{abstract}
The authors of the article consider the problems of professional and personal competence development adequate to the digital economy challenges. They emphasized that it is necessary to shift the emphasis from obtaining only the knowledge component to a personality-oriented, developing cognitive activity in the traditional education system. The task of the modern education system should be to teach the listener to learn. As you know, the digital economy is based on the idea of transaction cost reduction because people are removed from value chains. Routine operations will be automated, and a number of professional activities will disappear. This will affect the labor market and its structure; in order to maintain his competitiveness, a person will have to look for a new application and complete his profile of professional competence quickly. In the age of innovation and rapid development of IT technologies, human capital will become the main economic resource of companies. It is the rational use of each person potential, the creation of conditions for his harmonious development that will determine a company competitive position in the market. The business community and the education system should become business partners that mutually influence each other in the context of digital transformation.
\end{abstract}

Keywords: competence, professional skills, human capital, digital economy, education system, economic resource, information, professional activity, qualification level, knowledge.

JEL:J24

DOI: 10.5937/intrev2103130E

UDC: 331.548

005.963:[005.336.5:004

COBISS.SR-ID 55132169 


\section{INTRODUCTION}

Today, the world is on the verge of a radical transformation, the depth of which we have to assess yet. The key factor of a new society development is information, which is transformed into knowledge with a person's help. Of course, information has always been of great importance for the economy development, but only with the advent of digital technologies it has turned into an economic resource with which you can create additional value, and not only implement communication and cognitive functions.

The dynamism of the external environment leads to the rapid obsolescence of knowledge, there is such a concept as the shelf life of professional skills and abilities. A person is forced to carry out the learning process throughout his working life, constantly completing and updating his profile of competencies, and, if necessary, be ready to change the trajectory of his professional activity. It is the level of human resource qualifications, their knowledge and humanitarian understanding of the phenomenon essence taking place that create additional value in the value chain. For example, for such products as software, the degree of knowledge involvement in the process of their value development is close to $100 \%$.

According to the World Economic Forum, the digital sector development can provide additional stimuli for the world economy development and provide more than $\$ 30$ trillion dollars of revenues by 2025 [1]. Experts come to this conclusion based on the main meaning of digital transformation - a dramatic reduction in transaction costs and a change in their structure. In particular, by excluding a person from business value chains. According to the same World Economic Forum, robots can leave about 5 million people without work around the world during the next two - three years [14]. The researchers came to such a disappointing conclusion based on the analysis of data from 371 companies and 13.5 million of their employees in the states of Southeast Asia, the Persian Gulf, the USA, Great Britain, Germany, Italy, China, Turkey, France, Japan and other countries. Most of all reductions will affect office and administrative workers. It is expected that 4.7 million people may become unemployed in this area by 2020 . In the context of the ubiquitous spread of IT technologies, the once popular and even fashionable areas of activity (accountant, notary, document clerk, archivist, dispatcher and others) may disappear, their implementation will turn into routine operations, the execution of which will be entrusted to robots and artificial intelligence. In this regard, a number of scholars express concerns about the possibility of such a phenomenon appearance as superfluous people.

The unemployment rate increase can have serious socio-political consequences. And nowadays, the leaders of the largest states of the planet and leading research institutes are trying to find optimal scenarios to solve this challenge, namely, they model various scenarios for professional competence development demanded by the digital economy and the ways of human capital rational use, realizing that evolution cannot be stopped or reversed.

\section{METHODOLOGY}

To conduct research in this area, the authors used comparative analysis and retrospective historical approach. These tools of methodological analysis are aimed at objective reflection of the phenomena under study, but from different epistemological aspects.

The purpose of comparative analysis is to identify the universal, that is, to determine the general contours of a social phenomenon existence and development, which can be an education system that has a centuries-old history of its formation. Throughout various stages of evolution, the education system has sought to form and develop the personal and professional qualities of a person, which are necessary for him and society to be included in socially significant and professional activities.

Unfortunately, today the comparative approach is used extremely rarely or very limitedly in scientific sources. Usually researchers use it to search for arguments to emphasize the opposite of a given institution or phenomenon in comparison with others. And they do not use a comparative approach to search for the universally significant, which creates the basis for ensuring continuity in a social phenomenon development. At one time, K. Marx emphasized that one should not limit oneself to general definitions, since they act as rational abstractions. Identifying them is preparatory work. To determine general trends, it is necessary to search for specific features, since the specificity can be distinguished more clearly against the background of universally significant. 
However, it is advisable to use the comparative method not in its pure form, as an independent analytical tool, but in combination with the method of materialistic dialectics, otherwise the comparison may not touch upon the main thing, and go into secondary details.

The retrospective historical approach is based on taking into account the relationship between the past, present and future development of the socio-economic organization, which is the educational system, its real dialectics. And without knowledge of the past, it is impossible to understand the present, as well as to offer recommendations and directions to improve the existing education system so that it becomes more adequate to the digital economy challenges.

The use of the abovementioned methodological approaches to the analysis of the phenomenon under study is caused by the desire for multidirectionality in explaining the reasons for the education system development as a socio-economic organization. We emphasize that application of different tools of methodological analysis to explain the essential features and prospects of the education system evolution on the principle of mutually exclusive leads to the exclusion of a multidimensional vision of the phenomenon under study.

\section{DISCUSSION}

The digital economy changes the nature of human activity and shows the directions of professional skill evolution. For example, such competencies as network self-identification of a person, digital literacy, environmental friendliness of thinking, risk-oriented goal-setting, continuous personal self-development and a number of others are becoming demanded.

Analysis of the demanded competency models in large Russian companies showed that nowadays there is the emphasis shift from the competencies of the hard skills group towards soft skills. These terms have come into the realm of business from military affairs. Back in 1959, it was established in the United States that not only the process of professional skill development - possession of weapons and technical skills (hard skills), but also universal skills - working with people and documents (soft skills) is of great importance for military personnel.

Let's highlight the most characteristic differences between hard skills and soft skills. It is believed that hard skills are uniform requirements for professional skills, regardless of a company. They are formed in educational institutions and there is usually a gradation according to the degree of difficulty concerning its mastering. As a rule, the degree of this kind of competence mastering is confirmed by various diplomas and certificates issued by educational institutions.

As for the soft skills group of competencies, these are universal social and psychological qualities of a person that are given to him from birth (charisma, temperament, etc.) or are acquired as a result of social interaction (leadership qualities, organizational skills, stress resistance, etc.) ... Mastering this kind of competence very often happens by trial and error. They do not depend on the chosen direction of professional activity, but can affect the image and demand for an employee in the professional field. To prove their possession, you need not certificates and diplomas, but the ratings from colleagues, customer reviews, and the opinions of managers.

The most demanded competencies from the soft skills group include the following: leadership, focus on results, openness to change, systematic thinking, customer focus, sociability. These competencies are demanded by such large companies as IBS, Sberbank, Rosatom, Russian Post, Sibur, Zarubezhneft, Rostelecom.

Leading research organizations and the researchers have joined the business community to discuss the required competencies in the emerging digital economy [2][3]. For example, the Institute of the Future (Palo Alto, USA) published the report "Professional skills of the future - 2020" in 2011, in which it presented the Maps of professional competencies among future specialists demanded by the labor market for public discussion [4] (see figure below). 


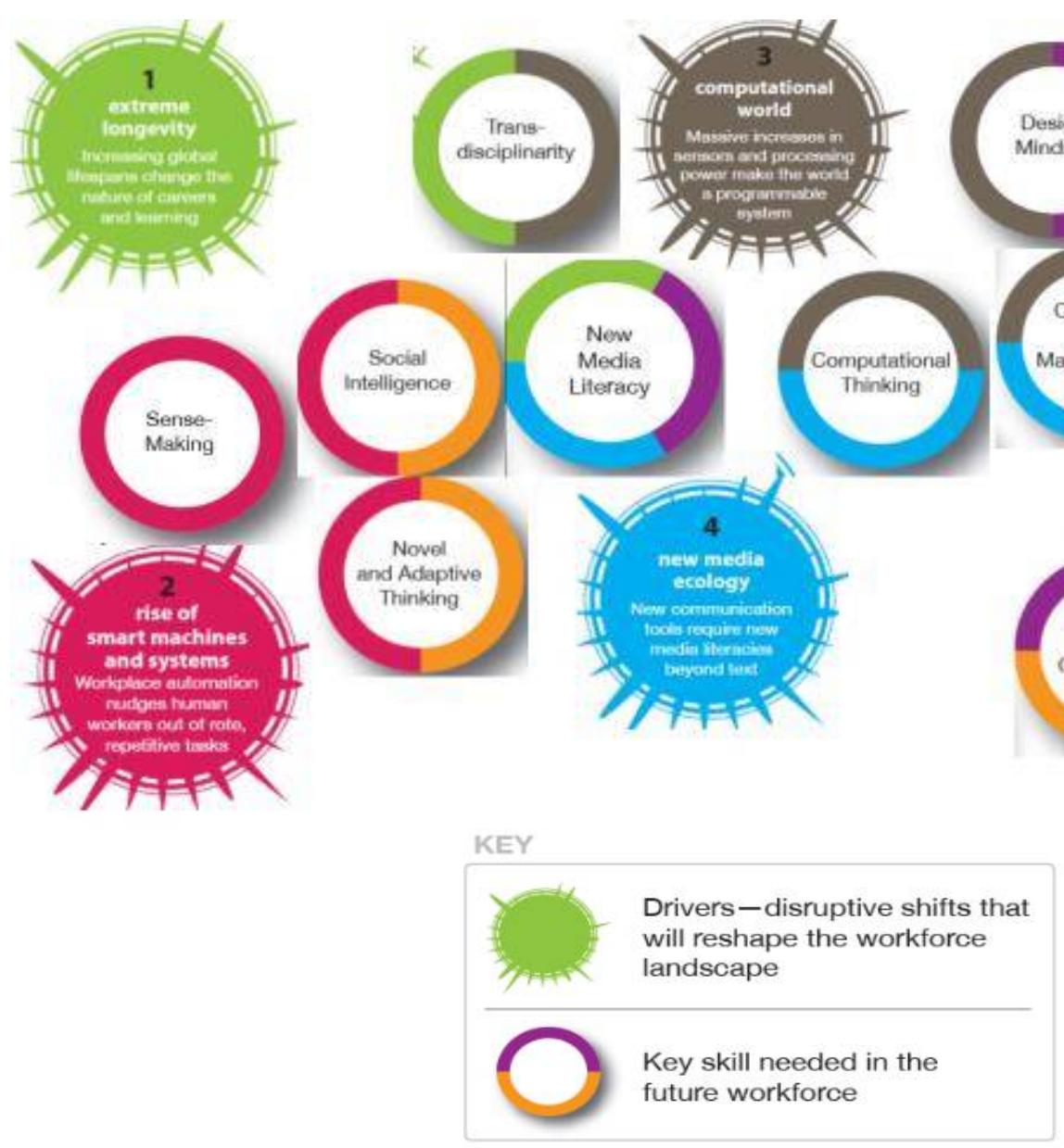

Fig.1. The map of future professional skills [4]

The Russian state also came up with an educational initiative. The Agency for Strategic Initiatives and the Moscow School of Management SKOLKOVO conducted a joint global study "Foresight of Competencies 2030", in which over 2,500 Russian and international researchers took part. The main objective of the study was to form "maps of the future" that would help define new competencies and shape the image of new professions. This will help those who start to choose their professional path to make the right choice.

Besides, Russia has launched the implementation of the national program "Digital Economy of the Russian Federation" and the federal project "Human Resources for the Digital Economy". The NTI University 20.35, the first Russian digital university [5], became the center of competence, a distinctive feature of which is the absence of traditional attributes inherent in a classical university. According to the experts, the university of the future is a digital platform that will unite people striving for self-development, where, instead of educational modules and courses, students will build an individual trajectory to achieve a unique set of competencies demanded by leading employers [6].

Thus, the general trend is the search for an optimal model to develop professional competencies adequate to the challenges of the digital economy and the rational use of human capital in the context of ubiquitous robotization.

\section{RESULTS}

We believe that the model of education of the future, taking into account the realities of the digital economy, should be similar to the model of the "learning organization" first characterized by C. Argyris and P. Senge [7][8][9][10][11]. As you know, the strengths of the "learning organization" model are the 
constant emphasis on learning, self-development, and self-improvement. This approach is typical not only for each employee, but also for the structural unit and a company as a whole.

Leaders in a "learning organization" understand that the competitive position of the organization is formed at the expense of its people. They are the main capital and economic resource that generate added value.

Changes in the external environment initiate experiments to improve the organization and management system in the internal environment of the company. This process takes place continuously, because if an organization does not flexibly respond to the changing conditions of its existence, then it can lose its economic stability and leave the market [12].

An example of a Russian company using the "learning organization" model is PJSC Rostelecom, which is the largest provider of digital services and solutions in Russia, as well as the largest employers providing jobs for more than 100 thousand people.

At PJSC Rostelecom, professional competencies are developed by independent structural units - the Knowledge Management Department and the Training Competence Center, bringing together effective internal mentors and the best external specialists and experts in the field of professional training.

Creating all the conditions for the harmonious development of each employee, the organization has developed criteria for assessing the status of an employee in its company. Such an indicator as the desire to develop further - professionally and personally, in order to increase the competitiveness of your organization is of key importance for an employee career growth and his remuneration increase.

The company is proud that every employee can offer his own idea to optimize business processes in an organization using modern digital applications, thereby contributing to its activity efficiency increase.

The organization strives to create all conditions for the personal and professional development of its employees. The company has a programming school that allows everyone to learn programming languages at the junior and middle levels. This will allow employees to gain additional competencies and the opportunity to change their profile of activities, which is especially important for those whose occupation is related to professions - retirees.

As innovations and IT technologies are the basis of the company activities and the factors of its competitiveness, the organization is constantly working towards the digital literacy increase among its personnel. To this end, the online series "Fundamentals of the Digital Economy" was developed, which includes nine online courses on digital technologies: external and internal experts of the company tell what data science is, the industrial Internet of things, blockchain, virtual reality, robotics, agile, digital marketing, quantum technologies and cybersecurity.

Online University is available for Rostelecom employees, containing more than 500 courses, to which a convenient tag search is configured for quick access, and portal navigation is optimized by content structuring.

Thus, modern organizations take on part of the functions to form the competencies necessary for their successful development. This approach is a necessary measure. Unfortunately, nowadays more than half of Russian universities do not have the opportunity to invest in their development, which means they cannot respond to the changing requirements of an innovative economy. Some universities (about 10\%) lack even a minimal digital infrastructure. In such conditions, companies strive to compensate for the problems of the modern education system, which is turning into a conservative institution that is unable to take into account the needs of the business community flexibly and promptly.

To change the current situation, which casts doubt on the necessity and significance of the education system, a radical reform of the latter is necessary.

We believe that information technology will make the education system more mobile and open. Nowadays, the Internet has simplified the collection and analysis of data required for scientific research, has provided equal access to knowledge for researchers from different countries, and has changed the way and channels for disseminating the results of scientific research.

Teachers and students got access to gaining knowledge in the virtual space. Information technology and the worldwide network have made it possible to develop online courses, to conduct massive open distance courses that compete with traditional educational programs and erase national boundaries.

The system of traditional education, in order to maintain its position, must give a certain freedom for students so that they can form an individual educational trajectory. Determine independently the variable 
part or additional modules, the so-called minors, whose purpose is to expand the scope of the student's professional activity and increase his demand in the labor market.

In addition, the structure of the educational program and its content must be publicly assessed by leading employers in this area. This will make it possible to form a "graphic portrait of an expert" with a set of competencies demanded by the labor market.

Another mechanism of partnership between business and the education system can be the opening of laboratories or departments directly on the territory of an organization. This will enable students to acquire the required practical skills in conditions as close as possible to their future professional activities. A harmonious combination of theoretical and practical training will contribute to a better training of experts demanded by the labor market.

The existing orientation of the traditional education system only for students to acquire a knowledge component or the formation of competencies in the hard skills group is no longer sufficient. Competencies from the soft skills group are more demanded by modern employers. In order to master this kind of competence, students need communication, and joint work. This can be achieved as the result of working on a joint project that will be implemented throughout the training and decomposed into the tasks within the various disciplines provided by the curriculum. For consultations and assessment of the final educational result, it is advisable to involve experts and mentors from the business community for the project. The student will have the opportunity to form a digital portfolio based on the results of the finished project, the reliability of the information in which will be guaranteed by the university and presented to the external environment [13].

In the new educational model, not only students should be assessed, but also teachers, the form and content of the educational process, as well as the mechanisms of interaction between the education system and the business community. This assessment will allow harmonize and update the components of the learning process much faster and more efficiently, promptly adjust the content of the educational process, based on the needs of the labor market, employers and a student himself.

\section{CONCLUSION}

The development of IT technologies and the widespread automation of production processes can lead to employment structure change in the labor market. Some of the professional tasks that are easily formalized will be performed by robots and artificial intelligence. A person will need skills to work in nonstandard conditions, flexibility of consciousness, to make creative decisions, as well as an integrated (systemic) approach to solve a problem. Besides, the ability to identify cause-and-effect relationships will be in demand, and the critical thinking will allow you not to get lost in the information flow and have your own view of the problem being solved.

Thus, there will be a shift in emphasis from the competencies of the hard skills group towards soft skills. However, the latter cannot be formed within the framework of the knowledge component mastering concerning the disciplines provided by the educational program. New forms of interaction between a teacher and students are needed, built on the principles of collaboration, teamwork, and expert consultation. All this can be achieved within the framework of teamwork on a project, where not an abstract set of acquired knowledge is offered for evaluation, but a finished product.

Project-oriented learning will allow moving away from a qualification model, in which professional skills are confirmed by diplomas and certificates, to a competency model, which will be based on a digital competency profile, and which will be formed and completed throughout the entire professional activity of a person.

\section{REFERENCES}

[1] Fedunenko E. Robots will come in peace // Kommersant. - 2018. - Sep 17. - URL: https://www.kommersant.ru/doc/3744298

[2] UNESCO Education Strategy 2014-2021. Paris, 2014. 61 p.

[3] Pellegrino J. W., Hilton M. L. (eds.), 2012 Education for life and work: Developing transferable knowledge and skills in the 21st century. Washington, DC: National Academies Press. 242 p. 
[4] Future Work Skills 2020 [Electronic resource]. Access mode:

https://uqpn.uq.edu.au/files/203/LIBBY\%20MARSHALL\%20future_work_skills_2020_full_researc h_report_final_1.pdf

[5] University 20.35 [Electronic resource]. Access mode: http://ncrao.rsvpu.ru/sites/default/files/library/universitet_20.35.pdf

[6] Tinyakova V. I., Morozova N.I., Gunin V. K., Kireeva O. I. (2019) Revival of the system of consumer cooperation in Russia; sustainable development of the territory and growth of quality life. Amazonia Investiga. 2019. V. 8. № 18. pp. 351-358. (In English)

[7] Argyris, C. and Schön, D. (1978, 1996), Organizational Learning II - Theory, Method, and Practice, Addi-son-Wesley, Reading

[8] Argyris, C. (1990), Overcoming Organizational Defenses -Facilitating Organizational Learning, Prentice-Hall,Englewood Cliffs, NJ.

[9] Argyris, C. (1992), On Organizational Learning, Blackwell,Cambridge.

[10] Argyris, C. (1993), Knowledge for Action - A Guide to Overcoming Barriers to Organizational Change, Jossey Bass, San Francisco, CA.

[11] Senge, P. (1990), The Fifth Discipline - The Art \& Practice of the Learning Organization, Sage, New York

[12] The Global Competitiveness Report (2018) K. Schwab (ed.). URL: http://www3.weforum.org/docs/GCR2018/05FullReport/TheGlobalCompetitivenessReport2018.pdf (In English)

[13] Tinyakova V.I., Morozova N.I., Ziroyan M.A., Falkovich E.B. (2018) Monitoring of human resources and a new educational structure for training specialists as key factors to reactivate the system of consumer cooperation in Russia. Amazonia Investiga. V. 7. № 17: pp. 353-359. (In English)

[14] Robots will deprive 5 million people of work by 2020 [Electronic resource]. Access mode: https://hi-tech.mail.ru/news/robots-people-2020-job/

\section{Article history:}

Received 28 October 2021

Accepted 30 November 2021 